\title{
ChemComm
}

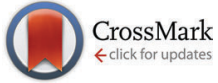

Cite this: Chem. Commun., 2016, 52,8294

Received 24th March 2016

Accepted 6th June 2016

DOI: $10.1039 / \mathrm{c} 6 \mathrm{cc0} 02556 \mathrm{k}$

www.rsc.org/chemcomm

\section{Carbogenically coated silica nanoparticles and their forensic applications $\dagger$}

\author{
D. Fernandes, ${ }^{a}$ M. J. Krysmann ${ }^{b}$ and A. Kelarakis ${ }^{\star^{a}}$
}

\begin{abstract}
Carbogenically coated silica nanoparticles $\left(\mathrm{C}-\mathrm{SiO}_{2}\right)$ exhibit colortunability and carry great promise for two important forensic applications. First, the $\mathrm{C}-\mathrm{SiO}_{2}$ nanopowders are ideal for fingerprint development, yielding strong contrast against multicoloured and patterned backgrounds. Second, spontaneous nanoparticle aggregation leads to non-duplicable, inexpensive nanotags that can support sustainable technologies to combat counterfeiting.
\end{abstract}

The remarkable photophysical properties of carbogenic nanoparticles (otherwise known as C-dots) are systematically explored in a variety of applications including printing inks, photocatalysis, biologically labelling, bioimaging and chemical sensing. ${ }^{1-5}$ Their non-toxic and biocompatible nature ${ }^{6,7}$ endows distinct advantages over conventional polyaromatic dyes and heavy metal-based quantum dots.

Large-scale and cost-effective synthesis of C-dots is realised via pyrolytic decomposition of virtually any type of carbon-rich precursors including plants tissue, ${ }^{8}$ natural saccharides, ${ }^{9,10}$ animal products ${ }^{11}$ and synthetic polymers. ${ }^{12,13}$ Alternatively, C-dots with varying graphitization degree are derived through disintegration, ${ }^{14}$ hydrothermal treatment ${ }^{15}$ and electrooxidation ${ }^{16}$ of carbon nanotubes, carbon nanofibers and graphite. In principle, quantum yield can be improved via surface passivation, ${ }^{17}$ heteroatom doping ${ }^{18}$ and the in situ formation of organic chromophores. ${ }^{19,20}$

In this report we focus on the exploitation of the advanced photophysical properties of carbogenically coated silica nanoparticles $\left(\mathrm{C}-\mathrm{SiO}_{2}\right)$ in two distinct forensic applications. First, we demonstrate that the colour-tuneable $\mathrm{C}-\mathrm{SiO}_{2}$ can be used as high performance nanopowders for latent fingerprint enhancement.

\footnotetext{
${ }^{a}$ Centre for Materials Science, School of Physical Sciences and Computing, University of Central Lancashire, Preston PR12HE, UK.

E-mail: akelarakis@uclan.ac.uk; Tel: +44(0) 17724172

${ }^{b}$ School of Pharmacy and Biosciences, University of Central Lancashire, Preston PR12HE, UK

$\dagger$ Electronic supplementary information (ESI) available: Detailed experimental section, TGA thermograph, FTIR spectra, AFIS analysis of fingerprints, hydrodynamic diameter and fluorescence images of fingerprints and nanotags. See DOI: $10.1039 / \mathrm{c} 6 \mathrm{cc} 02556 \mathrm{k}$
}

Second, spontaneous aggregation of the $\mathrm{C}_{-} \mathrm{SiO}_{2}$ during solvent evaporation generates non-duplicable photoluminescent motives that are ideal nanotags to mark and authenticate products. As reviewed recently a number of studies report the use of $\mathrm{SiO}_{2}$ based nanomaterials for fingerprint enhancement. ${ }^{21}$ Notable contributions focus on the use of surface modified $\mathrm{SiO}_{2}$ nanoparticles to gain insights into the mechanisms responsible for fingermark detection ${ }^{22}$ and the use of fluorescent dye-doped $\mathrm{SiO}_{2}$ nanoparticles to improve the image homogeneity and reduce donor inter-variability. ${ }^{23}$

To synthesize $\mathrm{C}_{-} \mathrm{SiO}_{2}$, colloidal silica was treated with dimethyloctadecyl[3-(trimethoxysilyl)propyl]ammonium chloride to give a product with $34 \mathrm{wt} \%$ organic content as determined by TGA (ESI, $\dagger$ Fig. S1). Subsequently, the product was pyrolysed at $250{ }^{\circ} \mathrm{C}$ before being subjected to surface oxidation via $\mathrm{HNO}_{3}$, amine functionalization and excessive dialysis against water. Elemental analysis of ${\mathrm{C}-\mathrm{SiO}_{2}}_{2}$ thus received suggests the presence of $26 \% \mathrm{C}$, along with minor amounts of $\mathrm{H}$ and $\mathrm{N}$ ( 4 and $5 \%$, respectively). The FTIR spectrum (ESI, $\dagger$ Fig. S2) shows peaks attributed ${ }^{24,25}$ to the vibrational stretching of $\mathrm{C}-\mathrm{H}\left(1380 \mathrm{~cm}^{-1}\right)$, the anti-symmetric and symmetric stretching vibrations of $\mathrm{N}-\mathrm{C}=\mathrm{O}\left(1550 \mathrm{~cm}^{-1}\right.$ and $1658 \mathrm{~cm}^{-1}$, respectively) and symmetric $\left(2850 \mathrm{~cm}^{-1}\right)$ and antisymmetric $\left(2920 \mathrm{~cm}^{-1}\right)$ stretching vibration of $\mathrm{sp}^{2} \mathrm{C}-\mathrm{H}$.

The TEM image of ${\mathrm{C}-\mathrm{SiO}_{2}}_{2}$ (Fig. 1) indicates the presence of spherical nanoparticles with average diameter $22 \pm 2 \mathrm{~nm}$. The nanoparticles are easily dispersed in water forming stable colloidal dispersions with $\mathrm{pH}=10.2$, consistent with the presence of surface functionalities generated through the acid/amine treatment. Fig. 2 suggests that the aqueous dispersions exhibit excitation wavelength dependent photoluminescent emission, in a manner similar to that observed for other carbon-based nanoemitters such as C-dots and graphene dots. The emission mechanism is not thoroughly understood, however contributions stemming from surface defects and the conjugated $\pi$-domains have been identified. ${ }^{26,27}$

The freeze-dried fine powder shows excellent flowability and can be easily applied to a variety of non-porous surfaces (ESI, $\dagger$ Fig. S3). The nanopowder adheres strongly to the fingerprints 


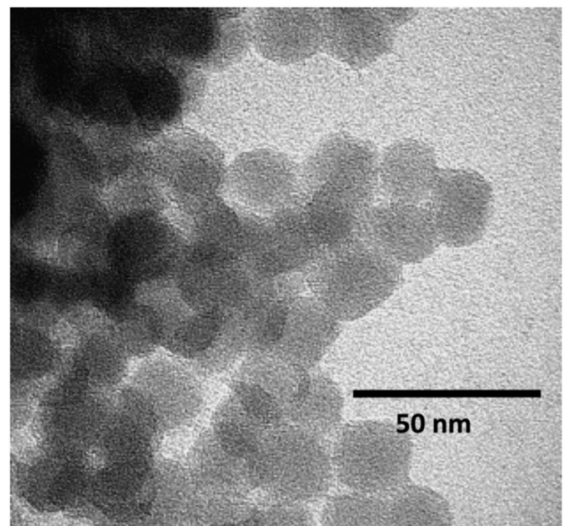

Fig. 1 TEM image of the $\mathrm{C}-\mathrm{SiO}_{2}$ nanoparticles.

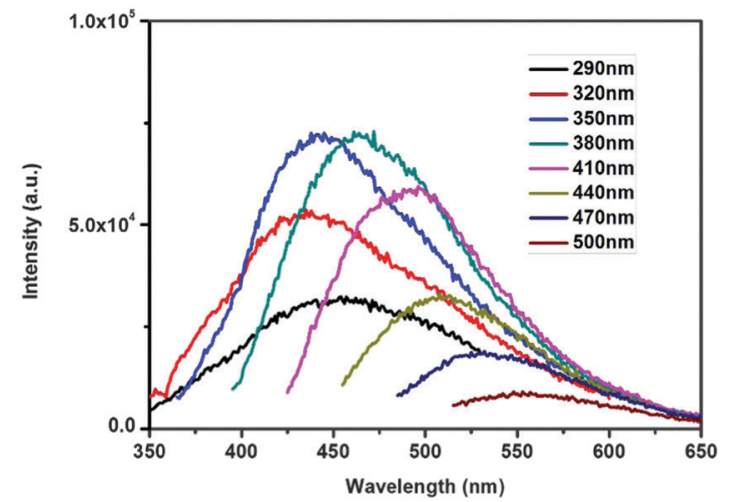

Fig. 2 Photoluminescence spectra of $\mathrm{C}-\mathrm{SiO}_{2}$ aqueous solutions under different excitation wavelengths.

revealing well-resolved patterns that meet the standard for individual identification (ESI, $\uparrow$ Fig. S3 and S4). Automated Fingerprint Identification System (AFIS) analysis of a fingerprint developed by $\mathrm{C}_{-} \mathrm{SiO}_{2}$ reveals 73 minutiae (details of a fingerprint such as ridge ending, ridge bifurcation, etc) compared to 65 minutiae for an identical fingerprint developed by a standard white fingerprint powder (WFP) (ESI, $\dagger$ Fig. S5).

Significantly, as shown in Fig. 3a the nanopowders exhibit colour-tunability and emit within the blue, green and red region when they are irradiated by violet, blue and green light, respectively. The supreme photophysical properties of $\mathrm{C}^{-\mathrm{SiO}_{2}}$ can open new horizons in forensic investigation by bypassing problems related to strong background interference from overlapping letters or fluorescent, multi-coloured and textured substrates. To demonstrate this behaviour, a set of fingerprints deposited on a highly fluorescent cardboard were developed under identical conditions using the $\mathrm{C}_{-} \mathrm{SiO}_{2}$ nanopowder and a commercial WFP, respectively. High quality images are collected for the $\mathrm{C}^{-\mathrm{SiO}_{2}}$ enhanced fingerprints (left image in Fig. 3b) under a $445 \mathrm{~nm}$ wavelength laser on a crime-lite imager. In contrast, the fingerprints developed using the standard WFP suffer from strong background interference leading to poor image quality (right image in Fig. 3b). A full set of images under the different wavelengths available on the crime lite imager can be seen in ESI, $\dagger$ Fig. S6. Moreover,

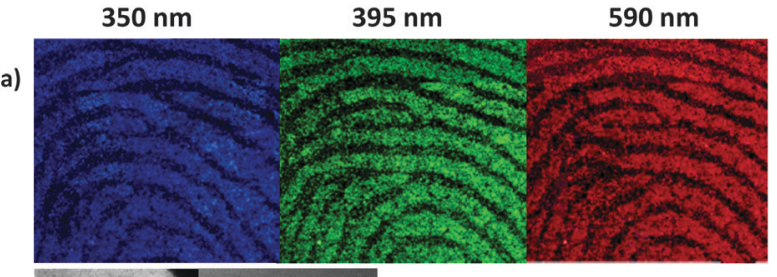

(b)

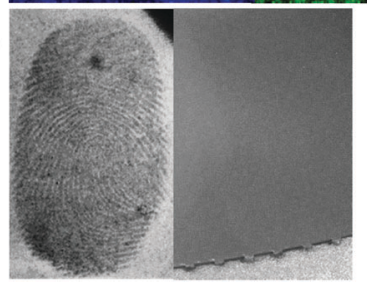

Fig. 3 (a) Fluorescent microscopy images of a fingerprint developed with the $\mathrm{C}-\mathrm{SiO}_{2}$ nanopowder. (b) Comparison between the $\mathrm{C}-\mathrm{SiO}_{2}$ and $\mathrm{a}$ commercial fingerprint powder on a fluorescent background investigated on a crime lite imager (445 nm laser with a $455 \mathrm{~nm}$ filter).

a fingerprint developed with $\mathrm{C}-\mathrm{SiO}_{2}$ compares favourably with that developed by a commercial fluorescent powder, in the sense that the latter shows strong contrast only under certain illumination wavelengths (ESI, $\dagger$ Fig. S7).

Fingerprint matching remains by far the most reliable biometric method used by law enforcement for individual identification, but its accuracy critically depends on the quality of the recovered impressions. To that end, a large number of fingerprint powders have been developed to maximize contrast against a variety of radically different substrates. In that sense, the use of a single, yet colour-tunable $\mathrm{C}_{-} \mathrm{SiO}_{2}$ nanopowder offers significant advantages in terms of dusting speed and image quality.

We have recently introduced a close related class of nanopowders comprising minor amounts of C-dots that also exhibit colour-tunability with respect to the incident radiation and, thus, are suitable for fingerprint enhancement. ${ }^{28}$ Another study describes the use of aqueous dispersions of C-dot/poly(dimethylacrylamide) nanocomposites for fingerprint detection. ${ }^{29}$ Notably, nanopowders with high C-dot content are not photoactive, presumably due to extensive self-quenching effects. ${ }^{30} \mathrm{~A}$ recent study suggests that blue, green and tan silicon-carbon dots/silica nanocomposite powders show adjustable optical properties as a function of their composition and structure. ${ }^{31}$ Here we demonstrate colour-tuneable nanopowders containing a single type of nanoparticles and are, thus, distinctly different from the nanocomposite and hybrid materials reported previously. The main advantage of $\mathrm{C}^{-\mathrm{SiO}_{2}}$ nanoparticles compared to C-dots based nanocomposites refers to their much larger carbogenic surface that holds great promise for selective and sensitive sensing of forensically important compounds found in fingerprints. We note that this report is a proof-of-concept investigation corresponding to phase 1 pilot studies as described by the International Fingerprint Research Group. ${ }^{32}$

When the $\mathrm{pH}$ of the aqueous suspension of $\mathrm{C}^{-\mathrm{SiO}_{2}}$ drops below 8.5, the colloidal stability is compromised as evident by the evolution of large aggregates (ESI, $\dagger$ Fig. S8). During water evaporation from an acidified dispersion, the $\mathrm{C}-\mathrm{SiO}_{2}$ were seen to undergo spontaneous and random self-assembly, giving rise 


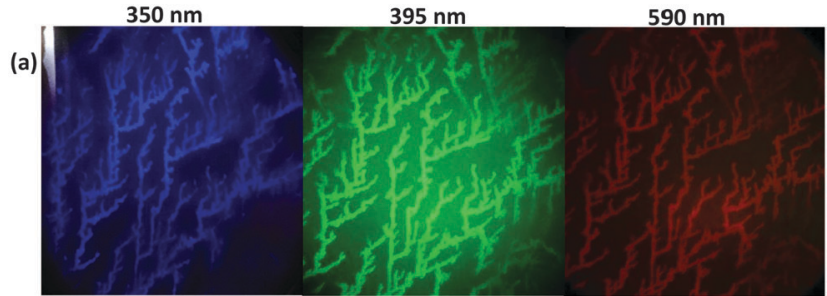

$395 \mathrm{~nm}$
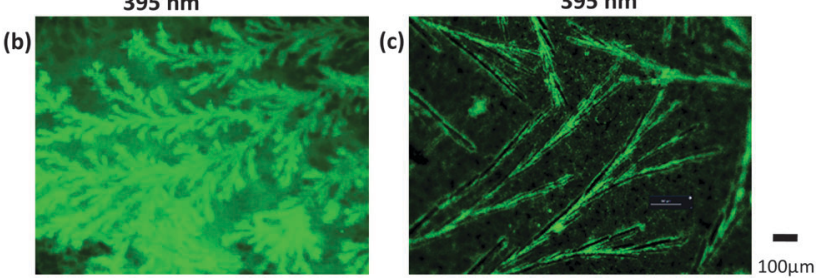

Fig. 4 Fluorescent microscopy images of the nanotags; (a) deposited in glass and illuminated under different excitation wavelengths, (b) deposited in glass from a more concentrated suspension, (c) deposited on a polymeric surface.

to motives that are highly fluorescent under laser radiation as shown in Fig. 4a. For comparison, we display two more images; one derived from a more concentrated dispersion (Fig. 4b) and one formed on a polymeric surface (Fig. 4c). (In contrast, no patterns are formed from dispersions with $\mathrm{pH}=10$, as shown in ESI, $\dagger$ Fig. S9).

The SEM images displayed in Fig. 5 reveal a high level of structural complexity confirming that the motives are nearly impossible to duplicate and can serve as nanotags for object authentication. The nanotags adhere strongly to a variety of substrates (polymers, metals, glass) and remain unaltered even after prolonged exposure to high temperature (ESI, $\dagger$ Fig. S10). We attribute this remarkable structural stability and durability to their organic-free and polymeric-free composition.

Suffice to say that counterfeit accounts for a 5-7\% world trade, causing a severe financial drain to the global economy. This crime deprives taxable income from bona fide business, discourages investment for innovation and inhibits social progress. Counterfeit drugs not only fail to cure, but they can cause severe health issues. Recent trends to address this problem rely on the use of upconverting nanocrystals ${ }^{33}$ and dye-doped nanoparticles $^{34}$ in integrated safety features and security graphics; however, those sophisticated compounds are often toxic and prohibitively expensive. In contrast, $\mathrm{C}-\mathrm{SiO}_{2}$ based nanotags are cost-effective and non-toxic for humans and the environment. Moreover, by virtue of their colour-tuneable nature, $\mathrm{C}-\mathrm{SiO}_{2}$ based nanotags impart enhanced security features, compared to commonly used dyes that display only one fixed colour.

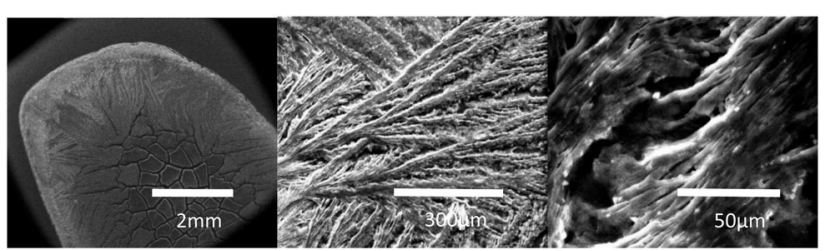

Fig. 5 SEM images of the formed patterns under different magnifications.
In conclusion, we introduce a new class of colour-tuneable nanomaterials $\left(\mathrm{C}_{-} \mathrm{SiO}_{2}\right)$ and we demonstrate their great potential in two distinct forensic applications. As fingerprint powders they circumvent problems stemming from poor image quality against multicoloured substrates. As nanoparticles that undergo spontaneous and random aggregation, they generate non-repeatable motives with a high level of structural complexity that can be used to mark and authenticate products. Those inexpensive and non-toxic nanotags are viable alternatives to current solutions with prohibitively high cost and they can support sustainable technologies to combat counterfeiting.

\section{References}

1 S. N. Baker and G. A. Baker, Angew. Chem., Int. Ed., 2010, 49, 6726-6744.

2 K. Hola, Y. Zhang, Y. Wang, E. P. Giannelis, R. Zboril and A. L. Rogach, Nano Today, 2014, 9, 590-603.

3 A. Kelarakis, MRS Energy Sustainability, 2014, 1, 1-15.

4 Y. Wang and A. Hu, J. Mater. Chem. C, 2014, 2, 6921-6939.

5 S. Y. Lim, W. Shen and Z. Gao, Chem. Soc. Rev., 2014, 44, 362-381.

6 H. Tao, K. Yang, Z. Ma, J. Wan, Y. Zhang, Z. Kang and Z. Liu, Small, 2012, 8, 281-290.

7 J. Wei, J. Shen, X. Zhang, S. Guo, J. Pan, X. Hou, H. Zhang, L. Wang and B. Feng, RSC Adv., 2013, 3, 13119-13122.

8 M. J. Krysmann, A. Kelarakis and E. P. Giannelis, Green Chem., 2012, 14, 3141-3145.

9 H. Peng and J. Travas-Sejdic, Chem. Mater., 2009, 21, 5563-5565.

10 L. Zhou, B. He and J. Huang, Chem. Commun., 2013, 49, 8078-8080.

11 J. Wang, C. F. Wang and S. Chen, Angew. Chem., Int. Ed., 2012, 51, 9297-9301.

12 J. Gu, W. Wang, Q. Zhang, Z. Meng, X. Jia and K. Xi, RSC Adv., 2013, 3, 15589-15591.

13 A. Jaiswal, S. S. Ghosh and A. Chattopadhyay, Chem. Commun., 2012, 48, 407-409.

14 L. Lin and S. Zhang, Chem. Commun., 2012, 48, 10177-10179.

15 D. Pan, J. Zhang, Z. Li and M. Wu, Adv. Mater., 2010, 22, 734-738.

16 J. Zhou, C. Booker, R. Li, X. Zhou, T. K. Sham, X. Sun and Z. Ding, J. Am. Chem. Soc., 2007, 129, 744-745.

17 H. Zheng, Q. Wang, Y. Long, H. Zhang, X. Huang and R. Zhu, Chem. Commun., 2011, 47, 10650-10652.

18 Y. Dong, H. Pang, H. Bin Yang, C. Guo, J. Shao, Y. Chi, C. M. Li and T. Yu, Angew. Chem., Int. Ed., 2013, 125, 7954-7958.

19 M. J. Krysmann, A. Kelarakis, P. Dallas and E. P. Giannelis, J. Am. Chem. Soc., 2012, 134, 747-750.

20 S. Zhu, X. Zhao, Y. Song, S. Lu and B. Yang, Nano Today, 2016, 11, 128-132.

21 A. Leśniewski, Synth. Met., 2016, DOI: 10.1016/j.synthmet.2016.03.032.

22 S. Moret, A. Bécue and C. Champod, Nanotechnology, 2014, 25, 1-10.

23 S. Moret, A. Bécue and C. Champod, Forensic Sci. Int., 2016, 259, 10-18.

24 X. Cui, L. Zhu, J. Wu, Y. Hou, P. Wang, Z. Wang and M. Yang, Biosens. Bioelectron., 2015, 63, 506-512.

25 L. Stobinski, B. Lesiak, L. Kover, J. Toth, S. Biniak, G. Trykowski and J. Judek, J. Alloys Compd., 2010, 501, 77-84.

26 A. Kelarakis, Curr. Opin. Colloid Interface Sci., 2015, 20, 354-361.

27 Z. Gan, H. Xu and Y. Hao, Nanoscale, 2016, 8, 7794-7807.

28 D. Fernandes, M. J. Krysmann and A. Kelarakis, Chem. Commun., 2015, 51, 4902-4905.

29 J. Dilag, H. Kobus, Y. Yu, C. T. Gibson and A. V. Ellis, Polym. Int., 2015, 64, 884-891.

30 S. Zhu, Q. Meng, L. Wang, J. Zhang, Y. Song, H. Jin, K. Zhang, H. Sun, H. Wang and B. Yang, Angew. Chem., Int. Ed., 2013, 52, 3953-3957.

31 C. Shih, P. Chen, G. Lin, C. Wang and H. Chang, ACS Nano, 2015, 9, 312-319.

32 International Fingerprint Research Group (IFRG), J. Forensic Identif., 2014, 64, 174-200.

33 N. M. Sangeetha, P. Moutet, D. Lagarde, G. Sallen, B. Urbaszek, X. Marie, G. Viau and L. Ressier, Nanoscale, 2013, 5, 9587-9592.

34 J. Kim, J. M. Yun, J. Jung, H. Song, J.-B. Kim and H. Ihee, Nanotechnology, 2014, 25, 155303. 